Dossier Anthropology on Latin America and the Caribbean today:

New Theoretical and Methodological Challenges

\title{
Una mirada antropológica a la usurpación de la identidad indígena en las elecciones de 2018 y 2021 en México
}

Laura R. Valladares'

'Departamento de antropología, Universidad Autónoma Metropolitana, Unidad Iztapalapa, México

\section{Resumen}

La construcción de una democracia plural con inclusión de las y los indígenas en condiciones de equidad tiene grandes retos, pues si bien las acciones afirmativas en materia electoral han registrado un avance relevante, la distancia entre las normas y su cumplimiento es enorme, por lo que la equidad electoral es todavía una asignatura pendiente, inicialmente porque existe una resistencia de los partidos políticos y los actores políticos para pluralizar el poder. El principal problema no se resuelve solamente en términos de técnica jurídica, es decir, de afinar los mecanismos de implementación y control de las acciones afirmativas, se trata de una situación compleja que tiene sus raíces en una cultura en donde el racismo frente a la diversidad étnica está vigente y la corrupción son su principal obstáculo. Esto se expresa con nitidez en los resultados de las contiendas electorales para elegir Diputados Federales en los Distritos Indígenas para las legislaturas LXIV (2018-2021) y LXV (2021-2024).

Palabras clave: Distritos indígenas, usurpación de la identidad indígena, racismo. 


\title{
An anthropological perspective at the usurpation of indigenous identity in the 2018 and 2021 elections in Mexico
}

\begin{abstract}
The construction of a plural democracy with the inclusion of indigenous people in conditions of equality has great challenges, because although affirmative actions in electoral matters have made significant progress, the distance between the norms and their compliance is enormous. Electoral equity is still a pending issue, initially because there is resistance from political parties and political actors to pluralize power. The main problem is not solved only in terms of legal technique, that is, to fine-tune the mechanisms of implementation and control of affirmative actions, it is a complex situation that has its roots in a culture where racism in the face of diversity Ethnicity is in force and corruption is its main obstacle. This is clearly expressed in the results of the electoral contests to elect Federal Deputies in the Indigenous Districts for the LXIV (2018-2021) and LXV (2021-2024) legislatures.
\end{abstract}

Keywords: Indigenous districts, usurpation of indigenous identity, racism.

\section{Um olhar antropológico sobre a usurpação da identidade indígena nas eleições de 2018 e 2021 no México}

\section{Resumo}

A construção de uma democracia plural com a inclusão dos indígenas em condições de igualdade apresenta grandes desafios, pois embora as ações afirmativas em matéria eleitoral tenham apresentado avanços significativos, a distância entre as normas e seu cumprimento é enorme. A equidade eleitoral ainda é um assunto pendente, inicialmente porque há resistência de partidos políticos e atores políticos em pluralizar o poder. O problema principal não se resolve apenas em termos de técnica jurídica, ou seja, para afinar os mecanismos de implementação e controle das ações afirmativas, é uma situação complexa que tem suas raízes em uma cultura onde prevalece o racismo versus diversidade étnica e a corrupção é o seu principal obstáculo. Isso está claramente expresso nos resultados das disputas eleitorais para eleição dos Deputados Federais nos Distritos Indígenas para as legislaturas LXIV (2018-2021) e LXV (2021-2024).

Palavras-chave: Distritos indígenas, usurpação da identidade indígena, racismo. 


\section{Una mirada antropológica a la usurpación de la identidad indígena en las elecciones de 2018 y 2021 en México}

Laura R. Valladares

\section{Introducción}

El estudio de los procesos electorales desde una perspectiva antropológica es relativamente reciente en México, los primeros estudios se realizaron desde el campo de la antropología política y del poder en los años setenta del siglo pasado y estaban interesados en general en el estudio de la cultura política para entender las lógicas del ejercicio del voto (Alonso, 1997:24). En la década de los ochenta los pocos estudios realizados se enfocaron a analizar la pérdida de legitimidad del longevo partido de Estado (PRI) y el aumento del abstencionismo, se privilegiaron miradas centradas en el conflicto y los nexos entre lo político y lo económico, así como las nuevas composiciones de la élite. Las reformas a la legislación electoral emprendidas de forma continua desde la década de los ochenta del siglo XX han sido un punto de partida para entender la aparición de partidos y la nueva competencia por el poder político con una oferta ideológica diversa. En el año de 1984 aparece por primera vez un número de la revista mexicana Nueva Antropología dedicado al tema electoral, cuyos artículos se centraron en los significados y nuevos campos de disputa que se abrieron con la reforma al artículo 115 constitucional, relativo al tercer nivel de gobierno, que son los municipios. Uno de los énfasis en los estudios antropológicos fue dar cuenta sobre el cómo se estructuraba y evolucionaba el campo político regional en sus relaciones con el poder económico y con la estructura social de la región. Temas tales como el cacicazgo político, la pluralidad partidaria, las alianzas, las rupturas en el poder tradicional fueron relevantes. Por esos años la antropóloga Silvia Gómez Tagle $(2015,2016)$ fue abriendo un espacio de reflexión antropológica de los procesos político electorales y ha tenido una continuidad y evolución muy significativa, así como el grupo de antropólogos dedicados a ello.

En lo que se refiere a los estudios antropológicos sobre disputas electorales en territorios indígenas, será hasta los años go que empieza a registrarse un interés por estudiar la forma en que se expresa el voto indígena en las contiendas electorales, sobre el pluripartidismo que se abría paso, así como la conformación de un movimiento indígena que luchaba por modificar sus condiciones de exclusión y exigía modificar la relación Estado-pueblos indígenas en clave autonómica. Intentando comprender cuestiones tales como ¿existe un voto indígena?, en qué partido militan o por cuál partido votan los indígenas?, ¿dejaron de ser parte del voto verde (campesino) que por décadas otorgó su apoyo al PRI?, ¿ ¿ómo se posicionan en el debate nacional sobre representatividad y el pluralismo? o sobre cuál era la agenda que buscaban posicionar en el Congreso de la Unión. Los estudios han transitado por distintas vertientes, una dedicada a documentar y analizar las disputas político electorales en los espacios municipales, especialmente en lo referente al control de los ayuntamientos y acerca de las luchas por ejercer su derecho a la autonomía, sobre lo cual existe una abundante producción. El otro campo analítico se ha centrado en el análisis de los impactos de las reformas electorales para garantizar el acceso de personas indígenas a una curul de los congresos locales y la Cámara Baja. Especial atención se ha dado a este último espacio, me parece a que esto se debe a que se constituye como una ventana que nos permite mirar problemáticas más amplias que el mero acceso a una curul, por ejemplo, sobre cuál es el lugar que tiene la problemática indígena en el modelo de estado nacional, así como explorar los orígenes y causalidades 
alrededor de las resistencias de los partidos políticos a incluir a las personas indígenas en las estructuras del poder legislativo. Es decir, si bien las elecciones son parte de la estructura político administrativa del Estado, son solo una parte del universo político, en tanto que los procesos políticos de todas las naciones son más amplios y más profundos que las instituciones formales destinadas a regularlas (Geertz, citado por Krotz, 1990:11), por ello que considero que estudiar las inclusiones y exclusiones de indígenas de la Cámara de Diputados son una arista que nos ofrece un observatorio muy sugerente si lo ubicamos en un contexto político socio espacial e histórico determinados, en donde el control por el poder en un modelo de Estado específico, se entretejen con una cultura racista, en donde la discriminación, clasismo y andocentrismo dan cuenta de las tensiones que construyen y explican la resistencias para construir una democracia plural.

Ahora bien, considerando las reformas electorales emprendidas a favor de los pueblos y personas indígenas en los últimos treinta años, que van desde las reformas a los códigos electorales locales hasta arribar a las acciones afirmativa para el acceso a curules en los congresos, existe un número interesante de investigaciones centradas especialmente sobre el rol de los y las indígenas en su gestión como legisladores o sobre los derroteros de las cuotas afirmativas. Algunos abordajes se han realizado desde una óptica del derecho (González, 2008), otras desde la sociología (Sonnleitner, 2013 y 2020) o desde la antropología política y/o jurídica (Pérez 2020, Valladares, 2018, 2020). A diferencia del abordaje sociológico, el antropológico no se basa, por lo general, en la construcción de indicadores cuantitativos, sino en un análisis cualitativo, en donde el contexto y los actores políticos son analizados en una arena política en la cual las culturas políticas, (indígenas, androcéntricas, pluralistas, etcétera) son fundamentales para entender las tramas de las disputas por el poder político en México. En la cual la pertenencia étnica no alude solamente a diferencias culturales, sino a modelos de nación y de ejercicio del poder distintos, que en ocasiones son coincidentes con los modelos y formas hegemónicas de ejercer el poder, pero en otras están en franca contraposición. El tema de las élites políticas que por décadas se han perpetuado en el poder es otra de las dimensiones que nos ayudan a entender las resistencias para pluralizar la democracia en nuestro país. Así mismo, siguiendo la tradición antropológica el relato etnográfico, la reconstrucción de las trayectorias, entrevistas, historias de vida, el análisis de los discursos y la gestión legislativa de las diputadas y diputados son fundamentales para entender los entramados, conflictos, alianzas y las confrontaciones con las que se construye el poder en la Cámara Baja, por ello el estudio de los entramados normativos y las acciones de los actores políticos en contextos específicos son de suma relevancia para comprender el papel que juegan las acciones afirmativas para pluralizar el ejercicio del poder.

\section{Los derroteros de las políticas afirmativas}

Las acciones afirmativas en materia electoral para personas indígenas en México representan un avance positivo para disminuir las desigualdades en materia de representación política, sin embargo, existe un abismo entre lo que señala la norma y su cumplimiento. Dichas acciones iniciaron con tibias reformas a los códigos electorales estatales en la década de los noventa del siglo XX, que conminaban a los partidos políticos a postular candidatos indígenas en aquellos municipios en donde la población indígena fuera considerable, sin embargo, no fueron acciones obligatorias y tuvieron muy poco impacto. En lo que corresponde al ámbito federal para la elección de Diputados, que es el centro de análisis de este artículo, las acciones afirmativas empezaron a diseñarse desde el año de 1996, cuando se realizó una modificación a los 300 Distritos electorales en que está dividido el país para la elección del mismo número de diputados de mayoría relativa (MR). En ese año el Instituto Nacional Electoral (INE), anunció 12 criterios-guía, con los cuales se pretendía abarcar preferentemente a pueblos, barrios, colonias, comunidades de población indígena integrada con base en aspectos socioculturales. 
Al término de esa re-distritación, el Instituto Nacional Indigenista (INI) concluyó que 37 de los 300 distritos federales electorales configurados ese año, el 12.3\%, podían considerarse indígenas debido a que el $30 \%$ o más de su población formaba parte de comunidades originarias (Báez, 2010). Desde entonces se han realizado por lo menos seis reformas emanadas de modificaciones a la ley electoral, de Acuerdos del INE y de Sentencias emitidas por el Consejo General del Tribunal Electoral del Poder Judicial de la Federación (TEPJF), encaminadas a fortalecer una estructura que permita el cumplimiento de la acción afirmativa dirigida a revertir la exclusión y sub representación de personas indígenas en la Cámara de Diputados, así como en los Congresos estatales (Cuadro número 1), sin embargo, como intentaremos mostrar en este texto no se trata solamente de técnica jurídica, sino de una cultura política, que se expresa especialmente en las acciones de los partidos políticos que se resisten pluralizar y democratizar sus estructuras partidarias para incorporar candidatas y candidatos indígenas.

Cuadro número 1: Reformas para el reconocimiento Distritos indígenas como parte de los 300

Distritos Electorales de mayoría relativa

\begin{tabular}{|c|c|c|c|c|c|}
\hline 1996 & 2004 & 2014 & 2017 & 2017 & 2020 \\
\hline Redistritación & Redistritación & $\begin{array}{l}\text { DOF "Decreto } \\
\text { por el que se } \\
\text { reforman, } \\
\text { adicionan y } \\
\text { derogan diversas } \\
\text { disposiciones de } \\
\text { la Constitución } \\
\text { Política de los } \\
\text { Estados Unidos } \\
\text { Mexicanos, en } \\
\text { materia política- } \\
\text { electoral }\end{array}$ & $\begin{array}{l}\text { Acuerdo INE/ } \\
\text { CG508/2017, } \\
\text { en cuanto a la } \\
\text { elegibilidad de } \\
\text { los candidatos a } \\
\text { Diputados en los } \\
\text { trece Distritos } \\
\text { Electorales indígenas }\end{array}$ & $\begin{array}{l}\text { Sentencia } \\
\text { dictada por la } \\
\text { Sala Superior } \\
\text { del Tribunal } \\
\text { Electoral del Poder } \\
\text { Judicial de la } \\
\text { Federación (SUP- } \\
\text { RAP-726/2017), } \\
\text { estableció el } \\
\text { cumplimiento de } \\
\text { la autoadscripción } \\
\text { calificada }\end{array}$ & $\begin{array}{l}\text { Acuerdo INE/ } \\
\text { CG572/2020 Se } \\
\text { incrementó de trece a } \\
\text { veintiuno el número } \\
\text { de Distritos en que los } \\
\text { partidos políticos o } \\
\text { coaliciones deberán } \\
\text { postular personas que } \\
\text { acrediten la adscripción } \\
\text { como indígenas de los } \\
\text { veintiocho distritos que } \\
\text { tienen un 40\% o más } \\
\text { de población indígena, } \\
\text { debiendo postular al } \\
\text { menos once mujeres. }\end{array}$ \\
\hline $\begin{array}{l}\text { El INI ubica } \\
37 \text { Distritos } \\
\text { Indígenas con } \\
30 \% \text { o más } \\
\text { población } \\
\text { indígena }\end{array}$ & $\begin{array}{l}\text { IFE reconoce } \\
28 \text { Distritos } \\
\text { Uninominales } \\
\text { indígenas con } \\
40 \% \text { o más } \\
\text { de población } \\
\text { indígena }\end{array}$ & $\begin{array}{l}\text { Se reconocen } \\
13 \text { Distritos } \\
\text { Indígenas }\end{array}$ & $\begin{array}{l}\text { Los partidos } \\
\text { políticos deberán } \\
\text { postular candidatos } \\
\text { indígenas para } \\
\text { la elección en } 13 \\
\text { Distritos en donde } \\
\text { más de } 60 \% \text { de } \\
\text { la población es } \\
\text { indígenas }\end{array}$ & $\begin{array}{l}\text { Los candidatos } \\
\text { a diputaciones } \\
\text { federales de los } 13 \\
\text { distritos indígenas } \\
\text { deberán expresar } \\
\text { y comprobar } \\
\text { auto adscripción } \\
\text { calificada. }\end{array}$ & $\begin{array}{l}\text { Se incrementó de } 13 \text { a } \\
21 \text { Distritos en donde } \\
\text { se deberán postular } \\
\text { candidatas y candidatas } \\
\text { indígenas. }\end{array}$ \\
\hline
\end{tabular}

Fuente: Elaboración propia con base en el Acuerdo INE/CG508/2017,

Sentencia del TEPJF (SUP-RAP-726/2017), y el Acuerdo del INE INE/CG572/2020.

Haciendo un apretado recuento de las reformas realizadas en materia electoral para personas indígenas en México para acceder a la Cámara de Diputados podemos señalar tres grandes modificaciones, relacionadas con la distribución de los 300 distritos electorales de mayoría relativa en los que se divide la geografía del país para la elección 300 de los 500 de Diputados Federales. La primera reforma fue realizada en 2004, en la cual INE reconoció la existencia 28 Distritos indígenas en donde la población indígena constituye el $40 \%$ o más de la población total (Báez, 2010:38). Con esta nueva geografía electoral podrían resultar electos el mismo número de diputadas y diputados indígenas. Lastimosamente esta distritación no logró revertir la sub representación, baste señalar que durante el último cuarto de siglo (1997 a 2021), que se corresponden con nueve legislaturas, el número de diputados indígenas rondó en un promedio de $9.8 \%$ (véase gráfica número 1 ). 
Es importante señalar que las cifras sobre el número de diputados de origen indígena que ofrecen las distintas investigaciones no coinciden y esto se debe a la dificultad para poder acceder a información exacta, pues es muy reciente que la pertenencia étnica sea un criterio para el registro de las y los candidatos. Adicionalmente, porque en los perfiles de los diputados publicados en la página del congreso no se ha registrado nunca la pertenencia étnica, en general se puede saber quien es indígena por su trayectoria, su plataforma política, por la o las organizaciones en las que militan, por su activismo a favor de los derechos de los pueblos indígenas, por su trabajo en la región a la que pertenece o porque hablan una lengua indígena, de tal forma que no es sencillo tener una cifra exacta de como se han constituido las bancadas indígenas en cada legislatura, por lo que debemos acudir de forma adicional a las trayectorias individuales, a la prensa nacional que da cuenta de los perfiles y distintos eventos políticos en que participan los candidatos, así como al trabajo etnográfico en la propia cámara de diputados, especialmente entre los integrantes de la Comisión de Pueblos Indígenas.

Gráfica 1: Diputados y Diputada indígenas por legislatura (1997 a 2021)

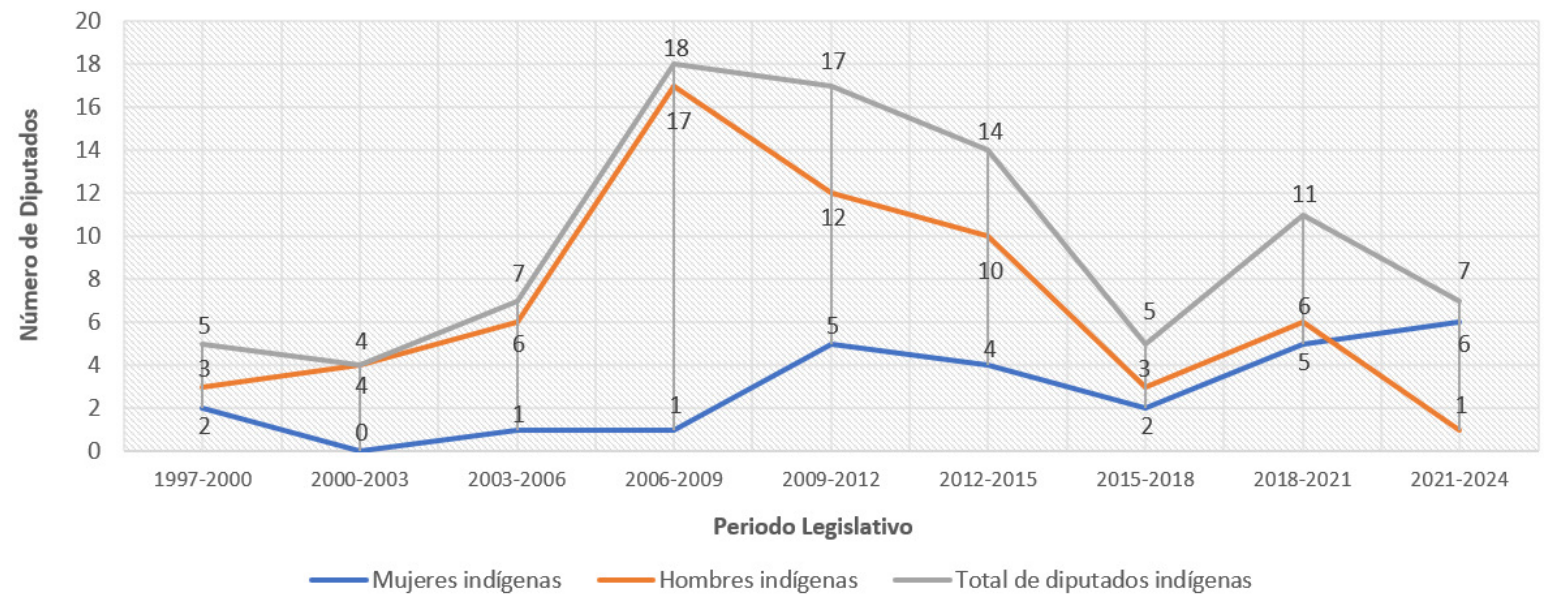

Fuente: Elaboración propia, a partir de los datos de Pérez (2020), Perfiles de los Legisladores y prensa.

Ahora, bien, regresando a las reformas en materia electoral, el INE aprobó en el año 2017 una nueva reforma que estableció la obligatoriedad de nominar a candidatos de origen indígena en trece Distritos Electorales, en los cuales la población indígena constituye el 60\% o más de la población total. Como veremos más adelante, a pesar del candado impuesto de demostrar la autoadscripción calificada para ser considerado como candidato en las elecciones del año 2018, no logró cumplirse la cuota afirmativa, pues en los trece distritos solo fueron elegidos seis personas indígenas, el resto de candidatos que accedieron a una curul lo hizo usurpando la identidad indígena. Un último Acuerdo importante del INE en materia indígena fue emitido en el año 2020 el 572 (INE/CG572/2020) con el cual se bajó el umbral del porcentaje de población indígena del 6o al 40\%, para hacer obligatorio postular a candidatas y candidatos indígenas pasando de 13 a 21 distritos electorales. Este modelo tuvo su debut en la última elección de julio de 2021 y sobre sus resultados presentaremos un primer acercamiento en este texto.

Dar seguimiento de los resultados de las acciones afirmativas para personas indígenas en las dos últimas elecciones correspondientes a las legislaturas LXIV (2018-2021) y LXV (2021-2024), es una oportunidad para dar cuenta de las deudas de la democracia para con los pueblos indígenas, así como para documentar las luchas, componendas y simulaciones que despliegan los partidos políticos para eludir las cuotas indígenas y con ello excluir a candidatos(as) indígenas. Esto es historia de larga data, lo que es novedoso son las estrategias utilizadas por los actores políticos, con el aval de sus partidos, para burlar las acciones afirmativas, especialmente la 
obligatoriedad de demostrar la identidad calificada, que implica no solamente declararse indígena, sino que las autoridades, comunidades, miembros u organizaciones indígenas te reconozcan como tal, en términos de Barth (1976) se requiere del hetero reconocimiento de la pertenencia étnica. Lastimosamente en las dos últimas elecciones hemos presenciado una inédita suplantación de la identidad indígena, la cual da cuenta de la falta de interés por disminuir las desigualdades históricas en la representación política de las personas y por tanto de los pueblos indígenas en la toma de decisiones a nivel nacional, así como una persistente necesidad de seguir afinando las normas electorales para el cumplimiento del espíritu de la acción afirmativa.

La eficacia de las cuotas afirmativas no solo depende de la pertinencia o candados con que se blinde la norma, sino del contexto regional-distrital de donde se eligen candidatos, es decir, tiene que ver con la solidez del sistema democrático, con la participación y correlación de fuerzas de las y los indígenas en el campo de las disputas por el poder local-federal. En este escenario, la suplantación de la identidad indígena es una expresión de una cultura que considera a los pueblos indígenas y sus problemáticas poco relevantes. Pues de acuerdo con el perfil de los y las candidatas que han incurrido en la usurpación de la identidad indígena, ni remotamente lo han hecho por un interés por abrogarse la representación indígena y "responder" a las demandas y necesidades de estas minorías socio políticas, sino que se trata de un fin más banal y corrupto, el interés individual por acceder a un cargo de representación, así como coadyuvar en la agenda de sus partidos de procedencia. En términos amplios, la usurpación de la identidad indígena da cuenta del lugar que tienen los pueblos indígenas en las plataformas y horizontes políticos de los partidos políticos, como en la política pública del país en su conjunto. Podemos constar que en muchos casos los usurpadores forman parte de una élite política que ha convertido los cargos de representación pública en un modo de vida. En términos sintéticos, los actos de usurpación de la identidad y con ello de suplantación de la representación política, denotan prácticas excluyentes de la diversidad étnica del país.

Las acciones afirmativas en materia electoral para pueblos y personas indígenas han debido recorrer un largo y sinuoso camino, y si bien responden a una política pública de inclusión de las minorías invisibilizadas y excluidas políticamente en la historia nacional, responden igualmente a una demanda expresada desde hace por lo menos 30 años por una parte del movimiento indígena para garantizar su derecho a participar en la toma de decisiones nacionales y aquellas referidas a sus pueblos. Sobre esta disputa podemos señalar la encabezada por del Frente Independiente de Pueblos Indígenas (FIPI) que en 1988 propuso crear una sexta circunscripción indígena constituida por 50 diputaciones por la vía de candidaturas plurinominales (Valladares, 2020). ${ }^{1}$ Unos años después, en el año 1994 como una de las resonancias del levantamiento zapatista en el estado de Chiapas, se llevó a cabo los días 4 y 5 de marzo de 1994, la Convención Nacional Electoral Indígena que reiteró la demanda de la configuración de una sexta circunscripción plurinominal para abrir espacios a representantes indígenas en la Cámara de Diputados. Unos años después la demanda fue retomada por la Asamblea Nacional Indígena Plural por la autonomía (ANIPA) ${ }^{2}$, sin que tuviera eco en el Congreso ni entre las autoridades electorales. Incluso esta organización logró su registro como Asociación Política Nacional (APN) en 1999, que es la antesala de la conformación de un partido político, encaminada a disputar espacios en la Cámara de Diputados, pero tampoco floreció (Burguete, 2007:154; Ruiz, 1999). Otro proyecto en este sentido fue la constitución de la denominada Asamblea Nacional Indígena en el año 2014, aglutinada para capacitarse

\footnotetext{
1 Adicional a los 300 distritos electorales, la geografía electoral del país está dividida en cinco circunscripciones electorales. De ellas son elegidos 200 diputados para completar la conformación de la Cámara de Diputados con 500 legisladores. Estos diputados son elegidos mediante el principio de la Representación Proporcional. Que funciona de la siguiente forma, de todos los votos acumulados en cada una de las circunscripciones se eligen 40 diputados cada una de ellas de acuerdo con el número de votos obtenidos por cada partido político. Se otorga la curul a partir de la lista de candidatos registrada por cada partido político. De allí que garantizar una curul, depende del lugar en que coloque cada partido a sus candidatos. Es decir, no dependen del voto ciudadano directo, sino del número de votos que obtiene cada partido.

2 La ANIPA, creada 1995, elaboró la primera propuesta de iniciativa de ley para reconocer la autonomía indígena en la constitución, que fue retomada por el EZLN, en las negociaciones con el gobierno federal emprendidas en el año de 1996 (Ruiz,1999).
} 
y cabildear para acceder a candidaturas de distintos cargos de representación estatal y federal, es decir, con fines eminentemente electorales. El más reciente intento de participación de indígenas en las elecciones fue la conformación de la denominada "Gobernatura Indígena Nacional" quien también ha buscado conformarse como partido político, con poco eco y visibilidad. Esta organización ha sido cuestionada por su lejanía con las demandas del movimiento indígena nacional, se les ha señalado por querer emular la estructura de los Consejos Supremos Indígenas creados por el Partido Revolucionario Institucional (PRI) en los años setenta del siglo pasado. ${ }^{3}$ Lo que me interesa destacar aquí es que la disputa por acceder a cargos de representación federal por personas y organizaciones indígenas no es nueva, aunque ha sido poco audible. Así mismo debo enfatizar que la disputa por acceder a curules en el Congreso de la Unión es enarbolada por un sector del movimiento indígena y no podríamos afirmar que existe como una corriente nacional.

Del escenario de disputa por la representación política de los pueblos y personas indígenas, considero que es importante hacer una precisión, por un lado, están los pueblos y comunidades que luchan por su derecho a elegir a sus representantes por medio de sus Sistemas Normativos Internos (SNI), en pleno ejercicio de su autonomía. Tales serían los casos de la autonomía de facto ejercida en los municipios zapatistas del estado de Chiapas desde la década de los noventa del siglo XX o las elecciones pioneras por "usos y costumbres" en el estado de Oaxaca (Recondo, 2014 y 2007). Por otro lado, están las experiencias de los municipios y comunidades que han logrado el reconocimiento de su derecho a elegir a sus autoridades sin la participación de los partidos políticos, después de largos procesos de disputa jurídica en los tribunales electorales como son los casos de Cherán en el estado de Michoacán (Aragón, 2019) Ayutla de los Libres en el estado de Guerrero (Benítez et. al, 2021) Oxchuc en Chiapas (Burguete, 2019) y Amilcingo en el estado de Morelos (Plá, 2020). A los que podemos sumar los municipios de Coatetelco, Hueyapan y Xoxocotla de este último estado, quienes durante esté año 2021 elegirán a sus autoridades por primera ocasión en Asambleas comunitarias. ${ }^{4}$ Seguramente se irán sumando otros municipios indígenas en el estado de Guerrero y otras entidades en donde existen municipios demandando este derecho.

Cuando nos referimos a los procesos electorales en los Distritos Electorales indígenas estamos hablando de un proceso político que tiene lógicas diferentes, pues en el ámbito municipal, son los integrantes del municipio quienes deciden la forma en la que elijen a sus autoridades. En el caso de los Distritos Indígenas, no son los y las indígenas quienes deciden de que forma elegirán a sus representantes para la Cámara de Diputados, son las normas electorales y las de los partidos políticos, por ello las acciones afirmativas están dirigidas a cumplirse por los partidos políticos, es decir, que son los partidos políticos los obligados a respetar las directrices electorales para postular candidatos indígenas. Por esta circunstancia la incidencia de los y las indígenas es reducida, pues los candidatos a diputados no emanan de una decisión tomada en una asamblea comunitaria, ni municipal, mucho menos de una asamblea distrital, la elección de candidatos a una diputación pasa por las lógicas y negociaciones al interior de los partidos políticos. Otra circunstancia alude a las dimensiones y conformación multi municipal de los distritos electorales, pues en pocas ocasiones coincide la relación pueblo indígenadistrito electoral. Al estar integrados por varios municipios, algunos tienen una composición pluriétnica, en otros la población indígena es mayoría, pero en otros son una minoría y se encuentran diseminados en varios municipios. Esto si nos referimos solamente a la distribución demográfico-territorial; a esta situación debemos sumar la pluralidad de partidos que disputan las candidaturas, a los poderes fácticos de grupos del crimen organizado que se han constituido como un actor que también disputa cargos de representación

\footnotetext{
3 Sobre la Gobernatura Indígena véase la nota periodística publicada por índice político: https:||indicepolitico.com/la-gobernatura-indigena-nacional-busca-conformarse-como-partido-politicol)

4 Sentencia SCM-JDC-88/2020 el Consejo Estatal Electoral del El Instituto Morelense de Procesos Electorales y Participación Ciudadana (Impepac) emitió los lineamientos para el registro y asignación de candidaturas indígenas que participarán en el proceso electoral 2020-2021. En el cuál se señala que se deberán elegir a sus representantes antes del 31 de diciembre de 2021, fecha en que concluye el periodo electoral de este año. véase: https://www.elsoldecuautla. com.mx/local/nuevos-municipios-indigenas-elegiran-a-sus-autoridades-por-usos-y-costumbres-6217037.html
} 
política en la estructura nacional o incluso las tensiones políticas inter comunitarias, entre otras variables que dan cuenta de la complejidad para lograr que se cumplan las políticas afirmativas en materia electoral. De esta complejidad, la condición más preocupante es la resistencia de los partidos políticos para postular candidatos y candidatas indígenas y su colusión para avalar a candidatos no indígenas. Se trata de una arena política en donde las alianzas, acuerdos y disputas determinan la repartición de cargos entre sus miembros destacados o visibles. Por ello no es casual que los partidos políticos se hayan inconformado y resistido a aceptar las nuevas directrices electorales, porque consideran que son una intromisión a su autonomía y aunque no prosperaron, han encontrado la forma de evadir o simular su cumplimiento.

También tenemos que considerar que el registro de las y los candidatos por parte de los partidos políticos se da en una arena de disputa política inter-e intra partidaria, de alianzas, de formación de coaliciones, de violencia, que en cada entidad federativa y por tanto en cada Distrito Electoral se refleja de distinta manera. Lo mismo habría que decir sobre las y los indígenas que se postulan como candidatos, algunos tienen una larga militancia en algún partido político, otros proceden de movimientos sociales y/o organizaciones indígenas, otros han tenido cargos de representación en las estructuras de sus pueblos y comunidades y algunos otros no tienen experiencia en cargos políticos, por ello no es posible hacer afirmaciones contundentes o generales sobre el perfil de los candidatos indígenas, por ello es importante analizar cada candidato, cada distrito tomando en consideración el contexto y los actores políticos involucrados.

Sin embargo, lo que si podemos afirmar de inicio es la enorme resistencia de los partidos políticos para dar cumplimiento a las cuotas afirmativas indígenas y a las correspondientes a la de paridad de género establecidas en el Acuerdo INE/CG508/2017, en cuanto a la elegibilidad de los candidatos a Diputados en los trece y luego en los veintiún Distritos Electorales indígenas en los cuales se buscaba garantizar el acceso de ese número de diputados indígenas a la Cámara de Diputados para los procesos electorales de 2018 y 2021 respectivamente. El incumplimiento de estas disposiciones y la lamentable experiencia de algunos candidatos no indígenas que se presentaron en proceso electoral del año 2018 llevaron a que se reconociera que no era suficiente la declaración de autoadscripción del candidato, por ello la Sentencia dictada por la Sala Superior del Tribunal Electoral del Poder Judicial de la Federación (TEPJF) (SUP-RAP-726/2017), estableció el cumplimiento de la autoadscripción calificada, en donde se señalan distintos medios de prueba para demostrar la pertenencia indígena de las y los candidatos. Entre estos demostrar el haber prestado servicios comunitarios o haber desempeñado algún cargo tradicional, haber participado en reuniones de trabajo tendentes a mejorar las instituciones indígenas, ser representante de una comunidad o asociación indígena que tenga como finalidad mejorar o conservar sus instituciones. Así mismo, se podrían presentar constancias expedidas por las autoridades comunales existentes en la comunidad o pueblo indígena, como pueden ser la Asamblea General Comunitaria o cualquier otra con representación conforme al sistema normativo vigente en la comunidad.

A pesar de esta estructura normativa los partidos políticos han encontrado la forma de evadirlas, en ocasiones en colusión con autoridades comunitarias, con la falsificación de documentos, con falsas promesas de apoyo a las comunidades expresadas por los candidatos que lleva a que algunas autoridades indígenas emitan documentos que avalan la pertenencia indígena, lo que es muy preocupante. Por estas razones, los casos que han sido denunciados por usurpación de la identidad indígena son complejos de comprobar por las autoridades electorales, por ejemplo, es difícil comprobar si una constancia es falsa, o si fue otorgada a través de un acto de corrupción. Otro de los grandes problemas se refiere a la amplitud que tienen las pruebas que se pueden presentar para demostrar la autoadscripción calificada, por ejemplo, el candidato al distrito de Tantoyuca, Veracruz había sido denunciado ante las autoridades electorales por usurpación de la calidad indígena, sin embargo, en la resolución emitida por los magistrados electorales se desestima el alegato argumentando que cumplía con el requisito de tener trabajo con la población indígena, lo cual no sólo es una interpretación desde mi perspectiva errónea, sino racista, que coloca a los indígenas como menores de edad que pueden ser 
representados por otros, esto me parece muy grave, porque sería tanto como afirmar que un hombre puede representar a las mujeres en tanto que tenga una trayectoria de trabajo a su favor. Sería no solamente inaudito, sino que generaría una cauda de impugnaciones y el rechazo abierto de las autoridades electorales y de las propias mujeres. Pero parece que en el caso indígena esto si es posible, lo que da cuenta de una visión que se niega a reconocer a los propios indígenas como actores políticos, los coloca como manipulables y presas de engaño o como menores de edad que pueden ser representados por otros. Ampliando lo oprobioso de esta situación, los diputados que incurrieron en la usurpación de la identidad, no mostraron interés en representar los intereses indígenas, como lo muestra el hecho de que ninguno se sumó a la comisión de pueblos indígenas de la Cámara de Diputados, con lo que se violenta no solamente la acción afirmativa, sino la posibilidad de que sean los propios indígenas los que ejerzan su derecho de auto representación.

\section{Los Diputados en los Distritos Indígenas para la LXIV Legislatura (2018-2021)}

En la elección de 2018, de los trece Distritos electorales en donde su población es del 60\% o más de origen indígena, se debieron registrar solamente candidatos(as) indígenas, sin embargo, solo seis de los candidatos y candidatas triunfadoras son de origen indígena. El caso más preocupante se vivió en Chiapas, pues es el estado en donde se concentran cinco de los trece distritos indígenas. En estos cinco distritos, se conoció ampliamente la suplantación de la identidad indígena de tres candidatos, dos funcionarios públicos de ese estado, militantes del partido verde: Humberto Pedrero candidato del Distrito o2 Bochil y Roberto Rubio Montejo por el distrito 11 Las Margaritas y la tercera suplantación estuvo encabezada por Manuela Obrador del partido Morena. En el estado de Hidalgo contendió y ganó una curul Fortunato Rivera por el Distrito Huejutla a quien en distintas ocasiones se le señaló como usurpador de la identidad indígena. Mientras que, en el estado de Oaxaca de los dos Distritos electorales indígenas con que cuenta, el de Tlacolula fue ganado por Azael Santiago, quien es un líder magisterial de larga trayectoria de lucha en la Coordinadora Nacional de Trabajadores de la Educación (CENTE), pero que no tiene indicios de un trabajo, ni un discurso a favor de los indígenas de la región o entidad que representó en el Congreso.

En lo que corresponde al Diputado veracruzano por el distrito de Tantoyuca Jesús Guzmán Avilés, tampoco es reconocido como indígena en ese distrito, cuya candidatura fue impugnada por el PVEM por suplantación de identidad indígena, pero al igual que en los casos denunciados en el estado de Chiapas tampoco prosperó el alegato. Al dar seguimiento periodístico a sus actos de campaña como a su labor legislativa, pudimos constatar que carecía de alusiones a la población indígena, nunca se refirió a la problemática indígena del Distrito o de su entidad y ya como diputado no se incorporó a la Comisión de Pueblos Indígenas. Señalo como dato significativo que dos de las tres candidaturas no indígenas del estado de Chiapas fueron avaladas por el mismo PVEM que en el caso de Veracruz, el mismo partido impugnaba por usurpación de la identidad al candidato de la coalición PAN-PRD-NA en el estado de Veracruz. Finalmente, en lo que corresponde a Yucatán el diputado Jesús Vidal Peniche, también ha sido señalado como usurpador de la identidad indígena, se trata de un político con una amplia participación institucional, pero en ella no muestra trabajo con la población maya y a pesar de esto se convirtió en diputado federal por el distrito de Valladolid (Valladares, 2020; Sonnleiner, 2020). De tal forma que de las 13 candidaturas indígenas solo seis podrían confirmarse la pertenencia indígena.

Ahora bien, los resultados electorales señalan que de la cuota indígena esperada ( 13 curules) se logró cubrir en un $46 \%$ muy reducida si consideramos que en esos distritos residen una población que es del $60 \%$ o más indígena (véase cuadro número 2). Ahora bien, a la cifra de seis diputados de origen indígena emanados de alguno de los trece distritos, debemos sumar otros cinco diputados de este origen, quienes accedieron a una curul por otros distritos que tienen una población indígena considerable pero que no formaban parte de la cuota establecida, cuatro resultaron electos en distritos de diferentes estados: Cipriano Charrez Pedraza por 
el Distrito 02 con cabecera en Ixmiquilapan, Hidalgo, Beatriz Dominga Pérez López del distrito o6 con sede en la ciudad de Tlaxiaco, Oaxaca y Bonifacio Aguilar Linda del distrito 18 de Zongolica, Veracruz (Sonnleitner, 2020:16). A los que debemos sumar la presencia de otra diputada de origen triqui, oriunda de Juxtlahuaca, quien accedió a la Cámara por la vía de una circunscripción plurinominal.

Cuadro Número 2: Diputados electos en los Distritos indígenas en la LXIV Legislatura 2018-2021 por partido político y pertenencia a la Comisión de Pueblos Indígenas

\begin{tabular}{|c|c|c|c|c|}
\hline Estado y Distrito & $\begin{array}{l}\% \\
\text { Población } \\
\text { indígena* }\end{array}$ & Diputado & Partido/coalición ${ }^{\star \star \star}$ & $\begin{array}{l}\text { Pertenencia a la } \\
\text { Comisión de } \\
\text { Pueblos Indígenas }\end{array}$ \\
\hline $\begin{array}{l}\text { Chiapas } \\
\text { 1.Palenque } \\
\text { 2. Bochil } \\
\text { 3. Ocosingo } \\
\text { 4. San Cristóbal de las Casas } \\
\text { 5. Las Margaritas }\end{array}$ & $\begin{array}{l}74.19 \% \\
75.31 \% \\
84.24 \% \\
73.68 \% \\
61.13 \% \\
\end{array}$ & $\begin{array}{l}\text { Manuela Obrador }{ }^{\star \star} \\
\text { Humberto Pedrero* } \\
\text { Alfredo Vázquez } \\
\text { Marta Dekket Gómez } \\
\text { Roberto Rubio** }\end{array}$ & $\begin{array}{l}\text { MORENA-PT-PES } \\
\text { PRI-PVEM-NA } \\
\text { MORENA-PT-PES } \\
\text { MORENA-PT-PES } \\
\text { PRI-PVE-PANAL }\end{array}$ & $\begin{array}{l}\text { No } \\
\text { No } \\
\text { SI } \\
\text { No } \\
\text { No }\end{array}$ \\
\hline $\begin{array}{l}\text { Guerrero } \\
6 . \text { Tlapa }\end{array}$ & $75.41 \%$ & Javier Manzano & MORENA-PT-PES & SI \\
\hline $\begin{array}{l}\text { Hidalgo } \\
\text { 7. Huejutla }\end{array}$ & $72.34 \%$ & Fortunato Rivera ${ }^{\star \star}$ & MORENA-PT-PES & SI \\
\hline $\begin{array}{l}\text { Oaxaca } \\
\text { 8. Teotitlán de Flores Magón } \\
\text { 9. Tlacolula }\end{array}$ & $\begin{array}{l}63.81 \\
60.42\end{array}$ & $\begin{array}{l}\text { Irma Juan Carlos } \\
\text { Azael Santiago }{ }^{\star \star}\end{array}$ & $\begin{array}{l}\text { MORENA-PT-PES } \\
\text { MORENA-PT-PES }\end{array}$ & $\begin{array}{l}\text { SI } \\
\text { No }\end{array}$ \\
\hline $\begin{array}{l}\text { San Luis Potosí } \\
\text { 10. Tamanzuchale }\end{array}$ & $72.57 \%$ & Marcelino Rivera & PAN-PRD-NA ${ }^{3}$ & SI \\
\hline $\begin{array}{l}\text { Veracruz } \\
\text { 11. Tantoyuca }\end{array}$ & 70.7 & Jesús Guzmán** & PAN-PRD-NA & No \\
\hline $\begin{array}{l}\text { Yucatán } \\
\text { 12. Valladolid } \\
\text { 13. Ticul }\end{array}$ & $\begin{array}{l}79.04 \\
83.72\end{array}$ & $\begin{array}{l}\text { Jesús Vidal Peniche** } \\
\text { Juan José Camul }\end{array}$ & $\begin{array}{l}\text { PRI-PVE-NA } \\
\text { PRI }\end{array}$ & $\begin{array}{l}\text { No } \\
\text { SI }\end{array}$ \\
\hline
\end{tabular}

Fuente: Elaboración propia a partir del Registro de candidaturas, página Web de la Cámara de Diputados, Prensa nacional y local.

* Acuerdo de INE/CG21/2021

** Diputados no indígenas registrados en Distritos Indígenas.

*** Coaliciones de partidos políticos: 1. "Juntos Haremos Historia”; MORENA: Movimiento de Regeneración Nacional, PT Partido del Trabajo y PES Partido Encuentro Social; “Todos por México”: PVEM; Partido Verde Ecologista de México; PRI Partido Revolucionario Institucional, NA Nueva Alianza; “Por México al frente”: PAN Partido Acción Nacional, PRD Partido de la Revolución Democrática, NA Nueva Alianza.

Una mirada rápida a los perfiles de los once diputados indígenas de la LXIV legislatura nos permite hacer algunas consideraciones generales, la primera es que todos y todas las legisladoras tienen una trayectoria sólida de militancia en distintos partidos políticos, es decir ninguno fue nombrado candidato indígena solo por su pertenencia indígena, sino por haber ocupado cargos relevantes previos a su nombramiento como candidato a diputado federal. Algunos habían sido presidentes municipales o incluso ya habían ocupado un curul en su estado o en la Cámara de Diputados Federal, cinco de los once diputados tienen esa experiencia previa: el diputado de origen Na Savi (mixteco) Javier Manzano, de militancia comunista, después Perredista (PRD) y actualmente Morenista, fue dos veces presidente municipal de Alcozahuca, Guerrero (1993-1996 y 1999-2002) y posteriormente Diputado Federal en la LIX Legislatura (2003-2006) y ya había sido candidato a una diputación federal en dos ocasiones previas, en 1997 y 2009. Adicionalmente, es pertinente mencionar que se trata de un importante distrito indígena, con población Mé phàà y Na Savi. El municipio de Alcozauca es famoso en nuestro país por haber sido el primero en ser gobernado por el partido comunista. El diputado es nieto del reconocido líder sindical Othón Salazar, quien fue uno de los promotores del partido comunista en 
la entidad guerrerense. ${ }^{5}$ En cuanto al diputado priísta (PRI) Juan José Camul actual diputado por el distrito 05 Ticul de Yucatán, ya había sido Diputado Local en la LIX Legislatura Yucatán (2010-2012) y había encabezado una serie de cargos en la estructura gubernamental de esa entidad. Mientras que el diputado panista (PAN) Marcelino Rivera, de origen huasteco, había sido previamente presidente municipal de San Martín Chalchicuautla, en San Luis Potosí (2012-2015). Por su parte el diputado de origen otomí del estado de Hidalgo Cipriano Charrez fue fundador del Movimiento Indígena Otomí (MIO) y fue presidente municipal de Ixmiquilpan (2012- 2016) y diputado local por el distrito 05 con cabecera en Ixmiquilpan para el periodo 2016-2018. Y finalmente, el diputado de origen nahua Bonifacio Aguilar, había sido presidente municipal de Soledad Atzompa, Veracruz en el periodo 2014-2017.

De los once legisladores(as) tres tienen una experiencia de activismo en defensa de los derechos de los derechos indígenas: Alfredo Vázquez Vázquez, con militancia en Chiapas en la ARIC Unión de Uniones Independiente y Democrática. Esta organización fue fundada en 1975, con el objetivo de defender la tierra y territorio de las comunidades indígenas tzeltales, tzotziles y tojol-ab’ales de las cañadas de la selva lacandona del municipio Ocosingo, Chiapas. Esta organización tiene un amplio trabajo en la creación de cooperativas y el trabajo en proyectos de agroecología y de equidad de género. Por su parte de las tres diputadas por el estado de Oaxaca, dos son de origen triqui, Beatriz Pérez y Virginia Merino, la primera es militante del Movimiento de Unificación y Lucha Triqui Independiente (MULTI), organización que tiene una larga historia de lucha por la autonomía de los triquis de San Juan Copala, disputa que ha estado marcada por el asesinado y desplazamiento de gran parte de los pobladores de ese municipio (De Marinis, 2016), la otra candidata triqui es maestra bilingüe y ha luchado por las derechos de las artesanas triquis y sobre la protección de los derechos sobre los diseños de los bordados indígenas. Mientras que la tercera diputada oaxaqueña, es la zapoteca Irma San Juan tiene una larga tradición de participación política primero en el PRD y después en Morena, en su cuenta de Facebook constantemente informa de su trabajo legislativo a favor de los pueblos indígenas y mantiene una relación estrecha con la población indígena del Distrito que representa, constantemente regresa a Oaxaca y participa en diversos eventos. Es la presidenta de la Comisión de Pueblos Indígenas y frecuentemente hace declaraciones sobre temas vinculados con los grandes problemas que aquejan a los pueblos indígenas. Se adhirió a veintiocho proyectos de decreto entre los que destacan por su contenido para la política pública hacia los pueblos indígenas, entre los que estuvieron la creación del Instituto Nacional de Pueblos Indígenas (INPI), así como del Proyecto de Decreto que adiciona y deroga diversas disposiciones de la Ley Minera y de la Ley General del Equilibrio Ecológico y la Protección al Ambiente. ${ }^{6}$ Este proyecto de Decreto tiene como objetivo "precisar los derechos de los pueblos y comunidades indígenas en materia de explotación minera e incluir en la evaluación del impacto ambiental, el grado de afectación que las obras puedan tener sobre las formas de vida de los pueblos indígenas y sus comunidades", fue presentado en octubre de 2018 y aún se encuentra pendiente de discusión y aprobación. De acuerdo a esta información me parece que la Diputada Irma Juan Carlos tiene uno de los mejores perfiles de la bancada indígena.

\footnotetext{
5 Líder oriundo de Alcozauca Guerrero (1924-2008), fue un destacado líder histórico del movimiento democrático de maestros en México. Estudio es las Escuelas Rurales de Oaxtepec, Ayotzinapa y en la Escuela Nacional de maestros. En 1953 encabezó un movimiento en contra del poderoso Sindicato Nacional de Trabajadores de la educación, del cual emergió el Movimiento Revolucionario del Magisterio (MRG) fundado en 1957 del cual Othón Salazar fue líder. Fue miembro del Partido Comunista Mexicano (PCM) y del Frente Electoral del Pueblo (FEP) se dice que participó en el movimiento guerrillero del estado, lo que le causó persecuciones políticas y encarcelamientos. En 1960 participó en la huelga nacional de Maestros encabezando la sección nueve del SNTE, que después crearía la Coordinadora Nacional de Trabajadores de la Educación, que hasta el día de hoy tiene un rol muy significativo en la lucha contra la reforma educativa emprendida en sexenio pasado.

6 Estas dos últimas presentada en conjunto por las Comisiones Unidas de Economía, Comercio y Competitividad, Medio Ambiente, Sustentabilidad, Cambio Climático y Recursos Naturales. Pueden consultarse en: http://sitl.diputados.gob.mx/LXIV_leg/curricula.php?dipt=200
} 
El caso de la diputada Marta Dekket es particular pues se le cuestionó su identidad indígena por ser hija de padre holandés y madre tseltal y por no tener trabajo a favor de los pueblos indígenas. Sin embargo, ha sido una activa legisladora y si bien no se sumó a la Comisión de Pueblos Indígenas, ha tenido una participación política interesante. Es integrante de las Comisiones de Igualdad de Género, Turismo y Medio Ambiente, Sustentabilidad, Cambio Climático y Recursos Naturales, ha tenido intervenciones en temas significativos. Por ejemplo, participó con el grupo de treinta diputadas federales que exigieron poner alto a la violencia política de género en el estado de Chiapas, ${ }^{7}$ tomaron la tribuna empuñando carteles con mensajes como "No a las Juanitas", "Ellas no entregan sus puestos" y "No sin mujeres". Las legisladoras hicieron un llamado a las autoridades chiapanecas para que emitieran las medidas cautelares necesarias para proteger a las 43 mujeres que renunciaron a sus cargos inmediatamente después de haber sido electas, (tenían listos a sus suplentes que serían hombres), la mayoría de las electas habían sido registradas por el Partido Verde Ecologista. Situación que dio cuenta de que habían sido colocadas como candidatas para cumplir con la paridad de género, pero con el acuerdo previo de renunciar en cuanto ganaran, entre ella había diputadas locales, presidentas municipales o síndicas, nuevamente este partido mostró su rostro corrupto y una simulación del cumplimiento de las cuotas género e indígenas que es lamentable. Las legisladoras federales exigieron que además de ser protegidas, se tenía que investigar a las personas que ejercieron presión para que presentaran sus renuncias (Pérez, 2020).

Otra de las actividades legislativas de la Diputada Marta Dekker tuvo que ver con la presentación de una Iniciativa de Ley para modificar el artículo 6 de la Ley Minera, en donde argumenta el daño que están haciendo las empresas nacionales y extranjeras que poseen concesiones sobre territorios de los pueblos indígenas, violando sus derechos fundamentales, como es el derecho a la consulta, previa libre e informada. Tema muy relevante si consideramos que existen cientos de concesiones en los etnoterritorios del país y un potente movimiento que lucha en contra de las empresas y sus concesiones. Otro de los temas que la diputada ha puesto a debate en la tribuna es el relativo la crisis de derechos humanos que atraviesan las familias mexicanas y migrantes, al ser deportadas y separadas de sus familias. Denunció la negligencia y opacidad con la que opera el gobierno federal y sus órdenes de gobierno, que han permitido que sean violentados los derechos humanos de las y los mexicanos que residen en el extranjero, así como la falta de compromiso con los fenómenos de transmigración de los que México es receptor (PMNOTICIASMX, 2018, Valladares, 2020).

Finalmente, la diputada nahua electa por el distrito de Ixmiquilpan, Hidalgo, Inés Parra Juárez pareciera que es la que menos actividad legislativa tuvo durante su gestión, lo que ha sido señalado por miembros de su partido (Morena). Junto con la Diputada Dekket son las únicas legisladoras que no tienen la experiencia previa de haber ocupado cargos de representación popular. La última legisladora de la bancada, es Irma Pineda en una entrevista señaló que su acceso a la política no ha sido sencillo pues sobre ella pesa una triple condición de exclusión y discriminación, por ser mujer, pobre e indígena. Por su participación de bajo perfil en la Cámara de Diputado los militantes de su partido se oponían a su reelección, pero a pesar de esta circunstancia logró reelegirse para la siguiente legislatura como veremos en poco más adelante (Rodríguez, 2019; López, 2021).

Como podemos ver se trata de una bancada indígena con un perfil interesante, con una eminente militancia en partidos políticos, forman parte de los líderes indígenas que han decidido dedicar su vida a ejercer cargo de representación popular y desde esa trinchera empujar la agenda indígena. Pero son una minoría que debe navegar en un congreso poco sensible a los temas indígenas. Los resultados electorales muestran que se mantiene una brecha de cumplimiento de la acción afirmativa. Fue ante esta situación el Consejo General

7 Véase nota número cuatro.

8 El término de "Juanitas" surgió en 2009, a raíz de que Rafael Acosta, apodado peyorativamente como Juanito, fuera postulado como candidato del PRD a jefe de la Delegación de Iztapalapa en la Ciudad de México, al que Andrés Manuel López Obrador condicionó a renunciar si resultaba ganador para dejar su lugar a Clara Brugada, candidata con menos posibilidades de ganar la contienda, y así se hizo. 
del INE (Acuerdo INE/CG572/2020), consideró indispensable incrementar de trece a veintiuno el número de Distritos en que los partidos políticos o coaliciones deberían postular personas que acrediten su adscripción calificada como indígenas en los veintiocho distritos electorales que tienen un $40 \%$ o más de población indígena. Debiendo postular al menos once mujeres en atención a la paridad de género. Enseguida veremos como quedó conformada la bancada indígena para la legislatura que entrará en funciones el próximo mes de septiembre de 2021.

\section{Los Diputados y diputadas electos(as) para la LXV Legislatura (2021-2024)}

En cuanto al proceso electoral celebrado el pasado 6 de julio para conformar la LXV legislatura, me gustaría iniciar señalando que ante la posibilidad de reelección de las y los disputados hasta por cuatro ocasiones, una primera batalla se dio entre los propios diputados y con sus partidos para recibir la venia para su reelección. En el caso de los diputados provenientes de los trece Distritos Indígenas la mayoría, tanto usurpadores de la identidad como los propios diputados indígenas, contendieron por la reelección y solo lo lograron cinco, dos indígenas: Alfredo Vázquez Vázquez (Ocosingo Chiapas) e Irma Juan Carlos (Teotitlán, Oaxaca) y tres diputados no indígenas volvieron a abrogarse una representación que no les corresponde: Manuela Obrador (Palenque, Chiapas), Roberto Rubio (Las Margaritas, Chiapas) y Azael Santiago (Tlacolula, Oaxaca). En el caso de los tres diputados no indígenas que contendieron, fueron exentados de presentar documentación que avalara su autoadscripción calificada, en tanto que ésta ya había sido valorada en su primera elección, lo cual pareciera absurdo para estos casos señalados como usurpadores, pero hasta ahora así están las normas electorales.

Para dar cuenta de la envergadura de los retos para hacer cumplir las acciones afirmativas, baste señalar que el diario El Economista reportó que el INE había detectado al menos 132 aspirantes a candidatos que habían "simulado" tener vínculos con pueblos o comunidades indígenas" (Badillo, 2021). Este dato muestra que a pesar de los controles del INE la cuota afirmativa para 21 legisladores era difícil de cubrirse. Solo he podido constatar la pertenencia indígena de siete candidatos, es decir, que a partir de estos datos la cuota indígena se cubrió en un $30 \%$, muy por debajo de lo logrado en la legislatura previa, que fue de un $46 \%$. Este porcentaje podría elevarse a un $42 \%$ si los candidatos del estado de Yucatán se auto adscriben como mayas, pero no encontré ningún dato que pudiera confirmarlo. En cuanto a paridad de género, si consideramos solo a las y los indígenas que serán legisladores, tenemos que serán seis mujeres y un hombre, de tal manera que será la primera ocasión que la bancada indígena esté conformada casi totalmente por mujeres.

Ahora bien, haciendo una primera revisión de los perfiles de los legisladores en ciernes, los resultados son preocupantes, pues por un lado, se mantiene la tendencia del perfil de los diputados de la legislatura saliente, es decir, la mayoría tiene una trayectoria en distintos cargos de representación y una militancia partidista sólida, se trata de actores(as) políticos(as) que saltan de un cargo a otro, que van escalando de cargos a nivel municipal, después a las legislaturas locales, para de allí contender por alguna curul en el Congreso de la Unión y después seguramente repetirán el ciclo.

Otra de las constantes es el continuo tránsito de los políticos de un partido a otro, lo que me parece que responde a distintas circunstancias, una relacionada con vaciamiento de las plataformas políticas de los partidos políticos, hasta hace dos décadas parecía claro que el PRD era un partido de izquierda, el PAN conservador de derecha, el PRI un partido de centro, y MORENA el de más reciente creación (2014) se posiciona con anti neoliberal, sin embargo, esto se ha diluido. Vivimos un escenario político nacional de pragmatismo extremo, en donde los candidatos cambian de un partido a otro, teniendo solo en consideración en dónde tendrán mejores garantías de triunfo. Esto tiene su origen con la pérdida de hegemonía del Partido Revolucionario Institucional (PRI) que por setenta años gobernó en el país y a los procesos de democratización que con enormes trabajos se abren camino en nuestro país. Su caída vino aparejada por la aparición de nuevos partidos o el 
fortalecimiento del segundo partido en términos de longevidad, el Partido Acción Nacional (PAN). En este escenario los políticos de todos los colores sin ningún reparo hacen coaliciones, alianzas y abandonan sus banderas ideológicas partidarias. Esta fluidez política se registra entre candidatos a Senadores, Gobernadores o presidentes municipales quienes, aún teniendo una larga trayectoria de militancia en un partido, en tiempos preelectorales pueden transitar sin el más mínimo prurito del partido conservador PAN, al discursivamente anti neoliberal Morena, o del PRD de centro izquierda al PAN, o del anquilosado PRI al Movimiento de Regeneración Nacional (Morena) (Valladares, 2020). Esto se agudizó en el proceso electoral de 2021 en donde los partidos políticos ante su virtual desplazamiento se apresuraron a acordar coaliciones, que en cada estado fueron distintas, pero con un reducido éxito. Esto lo demuestra el hecho de que, a pesar de la polarización política, la hegemonía del partido Gubernamental MORENA se amplió: tiene mayoría en las dos cámaras del Congreso de la Unión y gobierna en 17 de los 32 estados de la república.

Con este escenario, veamos ahora algunos datos de la trayectoria de los legisladores electos en los 21 Distritos indígenas (Véase cuadro número 3).

Cuadro número 3: Diputados electos en los 21 Distritos Indígenas para la LXV Legislatura Cámara de Diputados

\begin{tabular}{|c|c|c|c|c|}
\hline $\begin{array}{l}\text { Chiapas } \\
\text { MORENA } \\
\text { Manuela Obrador } \\
\end{array}$ & $\begin{array}{l}\text { Chiapas } \\
\text { MORENA } \\
\text { Adela Ramos* }\end{array}$ & $\begin{array}{l}\text { Chiapas } \\
\text { MORENA } \\
\text { Alfredo Vázquez* }\end{array}$ & $\begin{array}{l}\text { Chiapas } \\
\text { PRI-PRD-PAN } \\
\text { Yeimi Aguilar * }\end{array}$ & $\begin{array}{l}\text { Chiapas } \\
\text { PVEM } \\
\text { Roberto Rubio }\end{array}$ \\
\hline $\begin{array}{l}\text { Oaxaca (Teotitlán) } \\
\text { MORENA } \\
\text { Irma Juan Carlos* }\end{array}$ & $\begin{array}{l}\text { Oaxaca (Tlacolula) } \\
\text { MORENA } \\
\text { Azael Santiago }\end{array}$ & $\begin{array}{l}\text { Oaxaca (Huajuapan) } \\
\text { MORENA } \\
\text { Beatriz Pérez* }\end{array}$ & $\begin{array}{l}\text { Oaxaca (Ixtepec) } \\
\text { PVEM } \\
\text { José A Stefan } \\
\end{array}$ & $\begin{array}{l}\text { Oaxaca (Ixtlán) } \\
\text { MORENA } \\
\text { Carmen Bautista }\end{array}$ \\
\hline $\begin{array}{l}\text { Yucatán Valladolid } \\
\text { PAN } \\
\text { Sergio Chale }\end{array}$ & $\begin{array}{l}\text { Yucatán (Ticul) } \\
\text { PVEM } \\
\text { Carmen Navarro } \\
\end{array}$ & $\begin{array}{l}\text { Yucatán (Progreso) } \\
\text { PVEM } \\
\text { Xavier Peraza }\end{array}$ & $\begin{array}{l}\text { Guerrero (Tlapa) } \\
\text { PRD } \\
\text { Victoreano Wences }\end{array}$ & $\begin{array}{l}\text { Guerrero (Chilapa) } \\
\text { MORENA } \\
\text { Fabiola Rafael D* }\end{array}$ \\
\hline $\begin{array}{l}\text { Puebla (Zacatlán) } \\
\text { PVEM } \\
\text { Fátima Cruz }\end{array}$ & $\begin{array}{l}\text { Puebla (Ajalpan) } \\
\text { PVEM-PRI-MORENA } \\
\text { Inés Parra* }\end{array}$ & $\begin{array}{l}\text { Veracruz (Zongolica) } \\
\text { MORENA } \\
\text { Itzel Aleli Domínguez }\end{array}$ & $\begin{array}{l}\text { Veracruz (Tantoyuca) } \\
\text { PVEM-PT-MORENA } \\
\text { Carmen Pinete Vargas }\end{array}$ & $\begin{array}{l}\text { Hidalgo (Huejutla) } \\
\text { PRI-PAN-PRD } \\
\text { Sayonara Vargas }\end{array}$ \\
\hline $\begin{array}{l}\text { San Luis Potosí } \\
\text { (Tamanzuchale) } \\
\text { PVEM } \\
\text { Cristian Sánchez }\end{array}$ & & & & \\
\hline
\end{tabular}

* Diputados y diputadas de origen indígena.

Fuente: elaboración propia a partir de los perfiles de legisladores de la Cámara de Diputados Legislaturas LX, LXIII, LXIV, resultados electorales INE, prensa local y nacional.

En el distrito 02 de Bochil, Chiapas, se postuló Adela Ramos Juárez por el partido Morena. Es profesora perteneciente al SNTE, hizo campaña en varios municipios del Distrito y continuamente expresaba los principios que ha defendido su partido, como el siguiente:

El mando de nuestro pueblo debe estar seguro con un líder que lleve en sí mismo la gran escuela de lucha que es la política. No queremos más injusticias, somos un equipo que va de la mano caminando y luchando por los grandes cambios, por una equidad de género en cada toma de decisiones. La autenticidad de una persona originaria que conoce la trayectoria y la lucha que su pueblo ha tenido, es el mayor poder. Es un orgullo poder ser una persona honorable, que lleva la justicia y humildad para el crecimiento de su pueblo (Facebook Adela Ramos). 
Desafortunadamente no tenemos suficiente información, pero su candidatura no fue sencilla, porque Adela Ramos promovió un juicio de protección de sus derechos políticos electorales, en contra de la resolución dictada por la Comisión de Honestidad y Justicia del Partido Morena. ${ }^{9}$ Por su parte, la Red Nacional Indígena, denunció que esta candidatura había desplazado a candidatos indígenas de las zonas rurales. ${ }^{10}$

En el distrito 5 San Cristóbal de las Casas no logró ganar la reelección la Diputada Marta Dekket y la curul será ocupada por Yeimi Aguilar Cifuentes, también del sector magisterial y militante del PRI desde 2009, fue militante de la longeva Confederación Nacional Campesina (CNC), participó como coordinadora de la campaña en la elección del gobernador Chiapaneco Roberto Albores (2018), fue secretaria y consejera política local, estatal y nacional del PRI, presidenta del Comité ejecutivo del PRI en San Cristóbal de la Casas. ${ }^{11}$ En esta elección abandonó su larga militancia priísta para postularse como candidata de MORENA.

En el Distrito 10 Tamanzuchale, San Luis Potosí perdió la reelección el Diputado huasteco Marcelino Rivera y será sustituido por Christian Joaquín Sánchez, quien cuenta con una trayectoria política importante, en la cual no se percibe su pertenencia étnica o trabajo a favor de la población huasteca de la región, por el contrario en el año 2019 protagonizó en acto de violencia, al amenazar con un rifle AR-15 a un actuario y comuneros de Tampacán que intentaron ejecutar la resolución de un juez del Tribunal Unitario Agrario, quien ordenó la restitución de un predio de 27 hectáreas que poseía ilegalmente. Su trayectoria política de acceso a cargos de representación se remonta al año 2003, en el que fue regidor en Tampacán, para luego convertirse en alcalde de este municipio (2009-2012). Además, fungió como diputado local en la LX Legislatura del Congreso de San Luis Potosí (2012-2015), para posteriormente convertirse en diputado de mayoría relativa en la Cámara de Diputados por el PRI (2015-2018) por este mismo Distrito, será la tercera ocasión en que ocupa una curul, pero en esta ocasión fue candidato de la coalición encabezada por el PVEM. ${ }^{12}$

En lo que corresponde al Distrito 6 de Tlapa Guerrero, fue sustituido el diputado indígena Javier Manzano (MORENA), por Victoreano Wences Real (PRD) cuya candidatura fue impugnada por representantes de etnias indígenas al interior del partido Morena, lo acusaron de obtener un documento para acreditar su pertenencia a la comunidad de Ahuatepec, a la cual no pertenece. Es economista, con una maestría en Administración, fue Diputado Federal en la LXIII Legislatura (2015-2018), presidente municipal de Tlapa (2012- 2015), asesor de la Cámara de Diputados (2005 a 2008) y diputado local en el Congreso de Guerrero de 2008 a 2012.

En lo que corresponde a la curul del Distrito de Huejutla, del estado de Hidalgo, que estaba en manos de MORENA será ocupada por la priísta Sayonara Vargas Ramírez, quien también fue impugnada por la organización local Defensa de los pueblos indígenas, por considerarla impostora y sin calidad para acreditarse como representante de la región (Cabrera, 2021). En el estado de Yucatán los nuevos diputados serán los panistas Sergio Chale Cauich, por el Distrito de Valladolid y Consuelo del Carmen Navarrete Navarro por el Distrito de Ticul. El primero fue regidor del municipio de Tizimín y ha tenido varios cargos dentro de la estructura gubernamental de este estado. Mientras que la hoy diputada Carmen Navarro Navarrete, amenazó a su partido de que en caso de no registrarla como candidata impugnaría ante las autoridades electorales por violencia política de género, la amenaza funcionó y hoy es diputada federal. Es empresaria y en las entrevistas que ofreció en durante su campaña, señaló que impulsaría recursos para los campesinos. Aunque habrá que señalar que la población originara de la Yucatán se reconocen como mayas no como indígenas. Pero no logramos encontrar en sus presentaciones de campaña o en sus cargos previos, algún indicio sobre su pertenencia maya. Hasta aquí el relevo de las trece diputaciones indígenas en su segunda experiencia.

\footnotetext{
9 Véase: http://www.tribunalelectoralchiapas.gob.mx/estrados_electronicos/TEECH-JDC-294-2021-260421-2030.pdf

10 Véase la nota: https://laverdadjuarez.com/index.php/2021/04/05/exhiben-a-aspirantes-a-diputaciones-que-usurparon-espacios-indigenas/y https://averdadjuarez.com/index.php/2021/04/05/exhiben-a-aspirantes-a-diputaciones-que-usurparon-espacios-indigenas/

11 https://www.facebook.com/watch/?v=471366770880359

12 https://www.susanasolisinforma.com/cdata/dbfiles/dbcontenidos/dbdocs/2083.pdf
} 
Ahora bien, de los siete distritos que se adicionaron como cuota indígena para estas elecciones, el perfil de los diputados y diputadas ganadores es el siguiente:

Los tres nuevos distritos electorales del estado de Oaxaca en donde se estableció la cuota indígena, los resultados electorales fueron los siguientes: en Distrito 6 Huajuapan de León, el triunfo fue para Beatriz Pérez López abogada mixteca, que como hemos señalado, es actualmente diputada de la LXIV legislatura y fue reelecta para LXV Legislatura, con antecedentes políticos y activismo relevantes, ya había sido candidata para la Legislatura LXIII (2015-2018). Y tiene una sólida trayectoria como gestora social y jurídica del Movimiento de unificación y lucha triqui independiente (MULTI). El segundo distrito indígena oaxaqueño es Ixtlán, en donde resultó electo José Antonio Estefan Gillessen, quien ha transitado por varios partidos, del PRI al PRD y actualmente al PVEM. Es hijo del actual diputado federal, José Antonio Estefan Garfias, quien es militante del PRD y fue candidato a Gobernador. Es decir, el virtual diputado Estefan procede de un grupo de poder muy visible en la entidad oaxaqueña y no existe indicio de su pertenencia indígena o de trabajo con la población indígena de la entidad. El tercer distrito indígena es Ixtepec, correspondiente a la región del Istmo de Oaxaca, allí fue reelecta la morenista María del Carmen Bautista Peláez, quien es abogada de formación. Esta diputada en funciones accedió a la LXIV legislatura representando al Distrito de Puerto Escondido y en esta ocasión los hizo por el Distrito Ixtlán, cuya población es mayoritariamente zapoteca tampoco pudimos encontrar en las notas periodísticas de su campaña ni una sola alusión a su pertenencia indígena ni su compromiso con los indígenas del distrito que representa.

En el Estado de Guerrero, se anexó un nuevo Distrito, que es el distrito 6 con cabecera en Chilapa, en el cual ganó la diputación la maestra en educación pre-escolar indígena, Fabiola Rafael Dircio, quien fue síndica de Acatepec en el año 2015 y como parte de su trayectoria señala haber sido promotora comunitaria CONAFE y coordinadora de la combativa Coordinadora Nacional de Trabajadores de la Educación (CNTE).

En lo que corresponde al estado de Yucatán se sumó un nuevo distrito indígena, con lo que ya son tres con esta calidad, el distrito anexado es el número 2 con cabecera en la ciudad de Progreso, allí resultó electo Mario Xavier Peraza Ramírez, abogado de formación, militante del PVEM, candidato de la coalición "Juntos Hacemos Historia." El virtual diputado fue investigado por la Secretaría de Desarrollo Agrario, Territorial y Urbano (Sedatu) por presuntamente ser parte de un grupo criminal que se apoderó de varios terrenos en Yucatán. Esto cuando era director del Catastro en esa entidad entre 2012 y 2018, durante el gobierno del priísta Rolando Zapata. Estuvo involucrado en la venta de manera ilegal de tierras de la zona costera en contubernio con priistas. Se le acusa de haber falsificado documentos que llevaron al despojo de sus tierras a decenas de familias (Hernández, 2021). A pesar de estos antecedentes, fue postulado como candidato a diputado por el PVEM.

En el estado de Veracruz se anexaron dos nuevos distritos a la cuota de indígena, Zongolica y Tantoyuca. En el primero resultó ganadora Itzel Aleli Domínguez, de quien solo sabemos por datos de la prensa que es oriunda de la región y que inició su carrera política como brigadista y promotora de Morena con los pueblos nahuas. Pareciera que no era la candidata preferida de su partido, pero en virtud de la obligatoriedad de cumplir con el principio de paridad de género, fue considerada para esta diputación, aunque no tenemos la certeza de su pertenencia étnica. En el segundo distrito indígena fue electa María de Carmen Pinete Vargas, licenciada en educación básica y maestra en administración pública, se trata de una política de larga data, que inició su trayectoria política con distintos cargos en el Sindicato Nacional de Trabajadores de la Educación (SNTE) y en distintas instituciones desde 1985, fue presidenta municipal de Tantoyuca (1995-1997), Directora del Instituto Veracruzano para la Educación para Adultos (2000-2004), Diputada Federal en la LX legislatura (2006-2009), Diputada en la LXIII Legislatuta (2015-2018), candidata al Senado y ahora nuevamente Diputada Federal por el Distrito de Tantoyuca. Se trata de una política priísta cuya vida ha estado dedicada a la gestión pública, sin embargo, en ninguno de sus cargos o comisiones legislativas ha tenido que ver con pueblos indígenas. 
Finalmente en el estado de Puebla se incorporaron dos distritos electorales como parte de la cuota indígena: Zacatlán y Ajalpan, en el primero resultó electa Fátima Almendra Cruz Peláez por la coalisión MORENAPT-PVEM, es una abogada y educadora jóven, oriunda de Tetela del Volcán, localizado en la Sierra Norte de Puebla. Expresa su compromiso con todos los sectores sociales, entre ellos los indígenas. Sin embargo no tiene perfil indígena, ni en sus actos de campaña expresó tener dentro de su agenda política las demandas de los pueblos indígenas de la entidad. Finalmente, en el distrito de Ajalpan, la diputación será nuevamente ocupada por la profesora de origen nahua Inés Parra Juárez, quien como señalamos es actualmente diputada de la LXIV legislatura.

Lamentablemente los datos de los próximos legisladores no son alentadores, todo lo contrario, presenciamos disputas por el poder, que no tienen como base o alusión a la problemática de los pueblos indígenas a quienes representarán en la Cámara baja. Se trata de una bancada conformada mayoritariamente por una élite política cuyo horizonte apunta a su interés por perpetuarse en cargos de representación popular, sin importar las ideologías o plataformas políticas partidarias, en tales circunstancias los pocos indígenas deberán navegar en un contexto adverso que deja en vilo no solo la efectividad de las acciones afirmativas, sino los grandes problemas que aquejan a los pueblos indígenas de la república.

\section{Deudas de la democracia con las personas y pueblos indígenas}

Las cuotas afirmativas para personas indígenas en materia electoral son un avance relevante en cuanto a su objetivo de reducir la subrepresentación indígena en la Cámara de Diputados, sin embargo, hasta hoy en día han tenido un impacto poco significativo, pues se ha mantenido una presencia indígena marginal a lo largo del último cuarto de siglo. El periodo legislativo en que se registró el mayor número de legisladores indígenas fue en la LX legislatura (2006-2009), es decir cuando por primera vez se reconoció la existencia de distritos indígenas, en esa ocasión llegaron a una curul 18 legisladores, a partir de entonces se ha registrado una baja estrepitosa, llegando a tener solo 5 legisladores(as) en la LXIII legislatura (2015-2018), lo que representó un 1.\% del total de legisladores. En la siguiente legislatura (2018-2021), que corresponde a la legislatura en donde se estableció la cuota afirmativa demostrando la autoadscripción calificada arribaron 11 indígenas, quienes constituyen el 2.2\% del total de legislafores y en la próxima legislatura la LXV (2021-2024), solo habrá 6 legisladores de origen indígena, por lo que la bancada indígena será solamente del orden del 1.2\%. Lo que se traduce en que 5 legisladoras y un legislador indígena deberán luchar por colocar la agenda indígena como un tema a considerar en el Congreso, lo cuál parece poco probable.

Si nos referimos solamente al cumplimiento de las cuotas afirmativas en los Distritos de donde debían elegise candidatos y candidatos indígenas demostrando la autoadscripción calificada, en la legislatura LXIV de 13 Distritos solo arribaron cinco legisladores que se traduce en $38.4 \%$ de cumplimiento, mientras que en la LXV legislatura de 21 diputaciones reservadas solo fueron electos 7 indígenas, $30 \%$.

Cómo explicar la resistencia de los partidos políticos a cumplir con las cuotas afirmativas indígenas?. Un primera explicación podríamos colocarla en el ámbito de la construcción de la propia acción afimativa, que pudiera mejorarse, pero la más compleja tiene que que ver con las resistencias de los partidos políticos para reconocer el derecho de los y las indígenas a acceder a cargos de representación política en el Congreso de la Unión. Dicha resistencia da cuenta del reducido debate nacional sobre la problemática indígena y nos habla de la poca sensibilidad y compromiso con la contrucción de una democracia en donde la pluralidad cultural y política tengan un lugar. Expresa también un racismo estuctural, que coloca a los pueblos indígenas como un sector poco significativo y digno de estar en el Congreso de la Unión. La triple discriminación que pesa sobre los y las indígenas, por su condición de étnica, de clase y género, se expresa claramente en las condiendas electores, y pareciera compleja de remontar. Esta situación compleja en sí misma, debemos ubicarla en una 
arena de disputa política entre partidos políticos, entre longevas élites políticas y los nuevos actores políticos disputan el poder, en un modelo de nación en donde la problemática indígena es casi invisible e inaudible.

A pesar de este contexto adverso a la inclusión de la diversidad étnica, sería deseable afinar el contenido y las normas de la acción afirmativa, especialmente las dirigidas a los medios de prueba con los que se puede demostrar la autoadscripción calificada, los parámetros actuales son muy amplios, lo que ha permitido que personas no indígenas usurpen la identidad indígena, sobre todo en los que señalan que para demostrarla se bebe:

- Ser originaria/o descendiente de la comunidad y contar con elementos que acrediten su partidipación y compromiso comunitario

- Participar en reuniones de trabajo tendentes a mejorar dichas instituciones para resolver los conflictos que se presenten en torno a ellas, dentro la población, comunidad o Distrito indígena por el que pretenda ser postulado.

- Ser representante de alguna comunidad o asociación indígena que tenga como finalidad mejorar o conservar sus instituciones.

- Que "ha colaborado o trabajo a favor de una comunidad o pueblo" (Sentencias de la Sala Superior del TEPJF: SUP-RAP-726/2017.

Estos parámetros son lo suficientemente amplios para que personas no indígenas, se registren como indígenas, si muestran, por ejemplo, que han sido trabajadores de alguna institución gubernamental que tiene entre sus competencia el trabajo con población indígena o para quienes han participado en una organización que trabaja en alguna región indígena y esta situación se agraba si sumamos los casos en los que han entregado a las autoridades electorales documentos falsificados o que se han obtenido con actos de corrupción o falsas promesas de apoyo ofrecidos a las autoridades indígenas, situación que desvirtúa el espíritu de la acción afirmativa. Sería deseable acotar los criterios para demostrar la autoadscripción como por ejemplo contar con el aval de una Asamblea comunitaria de donde es originario el o la candidata, e incorporar otros que tienen que ver con las formas de organización y toma de decisión al interior de los pueblos indígenas,

Otra posibilidad podría ser retomar la propuesta de crear una sexta circunscripción o en su caso una circunscripción indígena reservada solo para el registro de candidatos indígenas que estaría conformada por cincuenta curules plurinominales, para lo cual se requeriría que cada una de las cinco circunscripciones existentes cediera diez de las cuarenta curules que la constituyen. Las doscientas curules plurinominales elegidas por el principio de representación proporcional son muy apreciadas, porque no dependen del voto ciudadano directo, pues son otorgadas a cada partido dependiendo del número de votos obtenidos en el proceso electoral. Esta propuesta ha sido reiterada desde 1990 y depende de la correlación de fuerzas que tenga el movimiento indígena, la bancada indígena y las autoridades electorales para que la pluralidad arribe a la cámara baja. Lo cual no parece cercano en el actual escenario nacional.

En distintos foros y debates en donde se discute salidas posibles a esta inequidad en la representación política indígena se ha planteado que otra posibilidad es salir de la lógica de los partidos políticos, es decir, que las diputaciones consideradas en la cuota afirmativa para personas indígenas sean registradas como candidaturas independientes, sin embargo, como podemos imaginar no se trata de solamente de técnica jurídica, sino de la capacidad de negociación en un campo político ahora con las autoridades electorales. Es justo reconocer que los indígenas han tenido como aliados y conocedores de la problemática indígena a algunos magistrados. Ha sido el sistema de justicia electoral la que ha reconocido el derechos de pueblos y comunidades indígena a elegir a sus autoridades de acuerdo a sus sistemas normativos, el INE se ha constituido como una válvula de escape para algunos conflictos políticos, sin embargo, aún falta mucho para que el INE, el Congreso de la Unión y los actores políticos consideren a los personas y pueblos indígenas como sujetos de derechos, la democracia tiene todavía una gran deuda con los pueblos y la personas indígenas. 
Recibido: 25 de julio 2021

Aceptado: 12 de agosto 2021

\section{Bibliografía citada}

ALONSO, JORGE. 1997. “Antropología política y elecciones en México”. Nueva Antropología, 51: 23-42.

ARAGÓN, Orlando. 2019. El derecho en insurrección. Hacia una antropología jurídica militante desde la expeiencia de Cherán, México. México: UNAM-ENES-Morelia.

BÁEZ, Adriana. 2010. "Impacto de los distritos electorales indígenas en los comicios de 2006 y 2009 ". Estudios Políticos, 19: 37-57.

BADILLO, Diego. 2021. "Despojan a candidatos indígenas de las candidaturas reservadas a comunidades originarias". El Economista, 9 de mayo. Disponible en: https:/|www.eleconomista.com.mx/politica/ Despojan-a-indigenas-de-candidaturas-reservadas-a-comunidades-originarias-20210509-0002.html [Consultada 17 de julio de 2021].

BENITEZ, David; WARNHOLTZ, Margarita; VARGAS Leslie (coord.). 2021. ¡Porque Ayutla es de los libres. La disputa por la autonomía municipal en Guerrero. México: UAM-Xochimilco.

BURGUETE, Araceli. 2019. "Elecciones por usos y costumbres en Oxchuc: los desafíos". Observatorio de las Democracias. Sur de México y Centroamérica. Disponible en: https:||observatoriodelasdemocracias.com.mx| covid-19/f/elecciones-por-usos-y-costumbres-en-oxchuc-los-desaf\%C $3 \%$ ADos [3o de junio 2021]

BURGUETE, Araceli. 2007. "De organizaciones indígenas a partidos étnicos: nuevas tendencias en las luchas indias en América Latina”. Liminar. Estudios Sociales y Humanísticos, V(2): 144-162 diciembre, Tuxtla Gutiérrez, Chiapas.

CABERA, Ángel. 2021. "Carecen de vínculos con esas comunidades 15 de los 21 diputados electos que representarán a los pueblos originarios", 24 hrs.mx. Disponible en: https:||www.24-horas.mx/2021/06/22/ se-agandallan-candidaturas-para-indigenas/[Consultado 15 de julio de 2021]

DE MARINIS, Natalia. 2016. "Mujeres indígenas ante los escenarios del miedo en México: (in)seguridad y resistencias en la región triqui de San Juan Copala, Oaxaca”. Estudios Latinoamericanos, año 34, núm. 44, julio-diciembre. UNAM, México. Disponible: http://revistas.unam.mx/index.php/rel/article/view/54723 [Consultado 10 julio 2021].

GÓMEZ TAGLE, Silvia (ed.). 2015. Alternativas para la democracia en América Latina, México: El Colegio de México/ Instituto Nacional Electoral.

GÓMEZ TAGLE, Silvia. 2016. "El reformismo electoral mexicano: límites y perspectivas”. Estudios sociológicos, 16(46): 147-171.

GONZÁLEZ, Jorge A. 2008. "La redistritación electoral y la participación política de los pueblos indígenas en México. Balance y perspectivas (2006-2009)". Boletín Mexicano de Derecho Comparado, Nueva Serie año XLI, número 121, enero-abril.

HERNÁNDEZ, Gabriela. 2021. "3 ex priistas, acusados de delitos, son candidatos de Morena en Yucatán”. Disponible en: https://www.sdpnoticias.com/estados/3-expriistas-acusados-de-delitos-son-candidatosde-morena-en-yucatan/ [Consultado 19 de julio 2021].

KROTZ, Esteban. 1990. "Antropología, elecciones y cultura política”. Nueva Antropología, XI(38): 9-38. 
LÓPEZ, Norberto. 2021. "Se reelige diputada Inés Parra sin tener productividad legislativa”, E-consulta.com. Disponible en: https:/www.e-consulta.com/nota/2021-06-11/nacion/se-reelige-diputada-ines-parra-sinproductividad-legislativa [Consultado 10 de junio 2021]

PMNOTICIASMX. 2018. "Diputada Marta Dekker Gómez denuncia la crisis de Derechos Humanos de las y los migrantes", 20 de septiembre de 2018. Disponible en: https://pmnoticiasmx.com/2018/og/20/diputadamarta-dekker-gomez-denuncia-la-crisis-de-derechos-humanos-de-las-y-los-migrantes/ [Consultado 2 de abril de 2019].

RECONDO, David. 2014. "Etos comunitario y derechos político-electorales del ciudadano en elecciones municipales por usos y costumbres. Evoluciones de la jurisprudencia electoral federal" http:/|portales. te.gob.mx/vii_observatorio/sites/default/files/Etos comunitario y derechos P-E..pdf [1o de octubre de 2018].

RECONDO David. 2007. La política del gatopardo: multiculturalismo y democracia en Oaxaca, México. México: CIESAS-CEMCA.

RODRÍGUEZ, Elizabeth. 2019. "Pide militante de Morena expulsión de ese partido de la diputada federal Inés Parra”. Disponible en: https://www.lajornadadeoriente.com.mx/puebla/pide-militante-de-morenaexpulsion-de-ese-partido-de-la-diputada-federal-ines-parra/ [Consultado 1ode junio 2021]

PÉREZ, Lizeth. 2020. "Retos de la representación política de las mujeres indígenas en el espacio legislativo". In: Laura Valladares y Gema Tabares (coord.), Activismo, diversidad y género Derechos de las mujeres indígenas y afromexicanas en tiempos de violencias en México. México: Juan Pablos Editores-UAM. pp. 211-247.

PLÁ, Camila. 2020. Memorias en contienda: Experiencias de resistencia y organización frente a los megaproyectos en Amilcingo Morelos. Tesina de Licenciatura en Antropología Social, UAM-Iztapalapa, México.

RUIZ, Margarito. 1999. "La ANIPA. Proceso de construcción de una propuesta legislativa autonómica nacional”. In: Araceli Burguete (coord.), México experiencias de autonomía indígenas. Copenhague: IWGIA. pp. 21-53.

SONNLEITNER, Willibald. 2020. "Participación, representación e inclusión política ¿Existe un voto indígena en México? In: Política y Gobierno, XXVIII(2): 1-39. Disponible en: http://www.politicaygobierno. cide.edu/index.php/pyg/article/view/1331/1025

SONNLEITNER, Willibald. 2013. "La representación legislativa de los indígenas en México: De la representatividad descriptiva, a una representación de mejor calidad", Temas Selectos de Derecho Electoral 32, México, Tribunal Electoral del Poder Judicial de la Federación (TEPJF).

VALLADARES, Laura. 2018. "Justicia electoral en Oaxaca: entre los derechos de las mujeres y los derechos comunitarios”. Alteridades, 28(55): 13-24.

VALLADARES, Laura. 2020. "Los dilemas de las cuotas afirmativas en materia electoral para los pueblos indígenas en México". Disponible en: https://www.academia.edu/44684968/Livro_Antropologia_ Politica_Indigena_EBOOK_15JUN [10 junio de 2021]

\section{Laura R. Valladares}

Departamento de antropología, Universidad Autónoma Metropolitana, Unidad Iztapalapa, México https://orcid.org/0000-0002-7577-6300

Email: lauravalladares.delacruz@gmail.com 